Portland State University

PDXScholar

6-3-1994

\title{
Impact of Goal-setting on Motivation as Affected by the Joint Influence of the Attributional Dimensions of Causality, Stability, and Control
}

Nancy Davis Hodges

Portland State University

Follow this and additional works at: https://pdxscholar.library.pdx.edu/open_access_etds

Part of the Psychology Commons

Let us know how access to this document benefits you.

\section{Recommended Citation}

Hodges, Nancy Davis, "Impact of Goal-setting on Motivation as Affected by the Joint Influence of the Attributional Dimensions of Causality, Stability, and Control" (1994). Dissertations and Theses. Paper 4859.

https://doi.org/10.15760/etd.6735

This Thesis is brought to you for free and open access. It has been accepted for inclusion in Dissertations and Theses by an authorized administrator of PDXScholar. Please contact us if we can make this document more accessible: pdxscholar@pdx.edu. 


\section{THESIS APPROVAL}

The abstract and thesis of Nancy Davis Hodges for the Master of Science in Psychology were presented June 3, 1994, and accepted by the thesis committee and the department.

COMMITTEE APPROVALS:

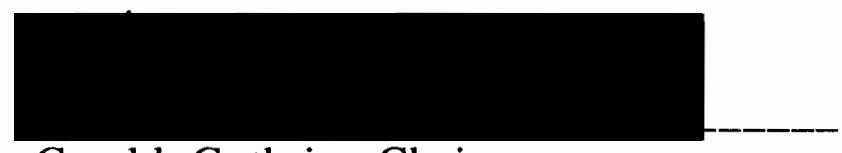

Gerald Guthrie, Chair
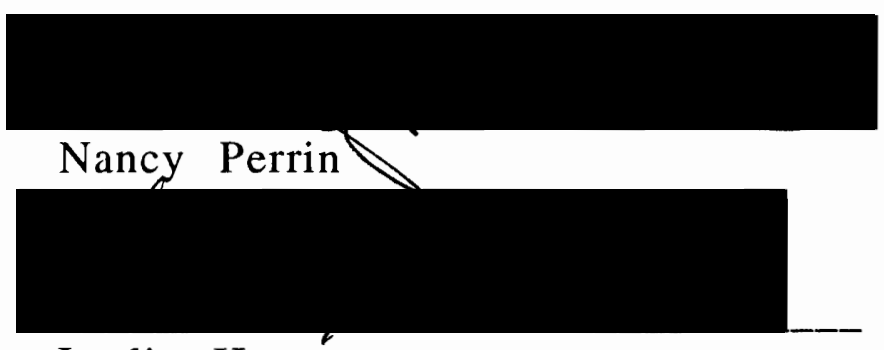

Leslie Hammer

DEPARTMENT APPROVAL:

James A. Paulson, Chair

Department of Psychology

$* * * * * * * * * * * * * * * * * * * * * * * * * * * * * * * * * * * * * * * * * * * * * * * * * * * * * * * * * * * * * * * * * * * * *$

ACCEPTED FOR PORTLAND STATE UNIVERSITY BY THE LIBRARY

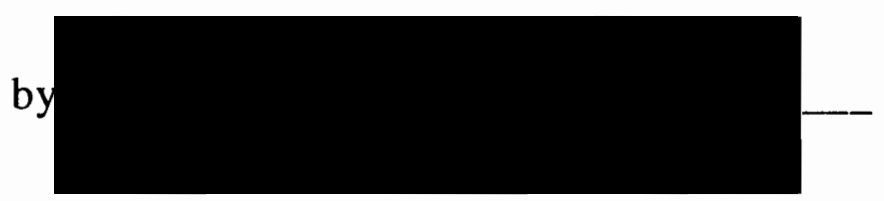

on

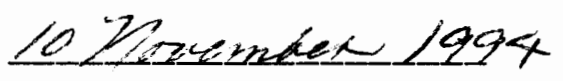




\section{ABSTRACT}

An abstract of the thesis of Nancy Davis Hodges for the Master of Science degree in Psychology presented May 3, 1994.

Title: Impact of Goal-setting on Motivation as Affected by the Joint Influence of the Attributional Dimensions of Causality, Stability, and Control

A systematic, empirical study conducted in eight hospital operating rooms found that employees often select opportunitydependent goals. These goals are self-set or chosen by the individual, but the opportunity to perform the goal chosen is dependent on others. For example, "learn to circulate on total joint surgeries" is a self-set, opportunity-dependent goal. The individual must be assigned to that job. It was found that when this type of goal is chosen and the individual is not given the opportunity to perform it, the individual attributes the failure to external causes. This failed opportunity-goal type was significantly related to lower motivation, whereas failed selfdependent goals (for example, "become more proficient on the computer") were related to higher motivation. It was found that the joint influence of the attributional dimensions of causality, stability, and control were affecting these differences for the two types of failed goal groups. 
IMPACT OF GOAL-SETTING ON MOTIVATION

AS AFFECTED BY THE JOINT INFLUENCE OF THE ATTRIBUTIONAL DIMENSIONS OF CAUSALITY, STABILITY, AND CONTROL

by

NANCY DAVIS HODGES

A thesis submitted in partial fulfillment of the

requirements for the degree of

\section{MASTER OF SCIENCE \\ in \\ PSYCHOLOGY}

Portland State University

1994 


\section{ACKNOWLEDGMENTS}

This project was completed as a thesis requirement for the Department of Psychology, Portland State University. I thank my indefatigable thesis advisor, Gerald Guthrie, for his unfailing encouragement and support. I also thank my thesis committee members, Nancy Perrin and Leslie Hammer for their thoughtful insights and suggestions. Appreciation is extended to the eight healthcare organizations, nursing administrators, research committees, and operating room managers. Special thanks is given to the registered nurses, surgical technicians, and OR assistants who volunteered to participate in this research project. Particular appreciation is felt for Bob, as well as, Kathryn, Joanna, and Ian for their generous faith, caring, and support. 


\section{TABLE OF CONTENTS}

PAGE

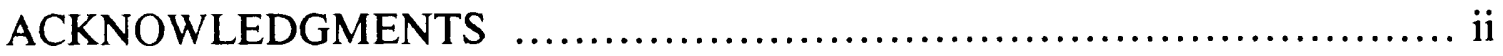

LIST OF TABLES...................................................... iv

INTRODUCTION ..................................................... 1

LITERATURE REVIEW .................................................. 4

Goal-setting....................................................... 4

Goal-setting Motivates Action

Goals Affect Performance

Factors Influencing goal-settings effect on performance

Attribution....................................................... 5

Personal Motivational Factors

Attributions for Outcomes

Attributional Dimensions

Attribution's Effect on Motivation

Description of Study.

Research Goals

Hypotheses

DATA COLLECTION.................................................... 13

Method........................................................ 13

Dependent Variables .......................................... 14

Attribution - Causal Dimension Scale

Motivation - Deci's Measures of Intrinsic Motivation

DATA ANALYSIS ...................................................... 16

Results.............................................................. 16

MANOVA

Newman-Kuels' Post-hoc Tests 
Regression Analysis

DISCUSSION............................................................ 21

Differences in Causality

Differences in Stability

Differences in Control

Differences in Motivation

Joint Influence of the Attributional Dimensions on Motivation

IMPLICATIONS FOR THE HOSPITAL SETTING........................ 26

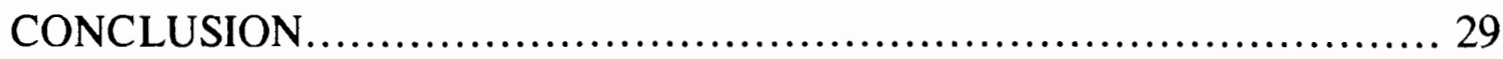

Limitations of the Study....................................... 29

Future Research................................................. 30

SUMMARY ............................................................. 32

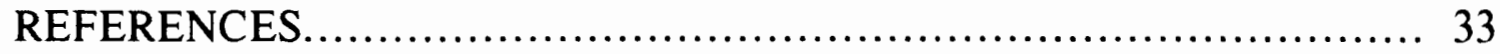

APPENDICIES 


\section{LIST OF TABLES}

TABLE PAGE

I Goals ....................................................... 2

II Dependent Variables ....................................... 8

III Independent Variables ....................................... 9

IV Explanation of Responses for Causal Dimension Scale ......... 10

V Means and Standard Deviations .............................. 17

VI Newman-Kuel's Post-hoc Significance Tests ................. 17

VII Regression Analysis ...................................... 20 


\section{INTRODUCTION}

Goals are defined as "setting and attaining a specific standard of proficiency on a task, usually within a specified time limit" (Locke, Shaw, Saari, \& Latham, 1981). Organizations adopt goal setting systems in order to increase motivation and improve performance. Specific goals for individuals may be assigned by management or selected by the individuals themselves. Researchers have explored how these self-versus other assigned goals influence performance (Erez \& Zidon, 1984; Locke, Latham, \& Erez, 1988). However, there are situations in industrial and organizational settings that make inadequate the simple distinction between self- and other-assigned goals. In these settings, there is a type of goal-setting which consists of the individual choosing a goal (selfassigned) whose success $(\mathrm{S})$ or failure $(\mathrm{F})$ is dependent upon some opportunity to attempt the goal, and access to this opportunity is itself dependent upon the decision of someone else (e.g. management.) This self-assigned type of goal will be referred to as an opportunity-dependent goal (OD) and is contrasted with the self-dependent goal (SD) whose opportunities for undertaking the goal are controlled by the individual (see Table 1). 
TABLE 1

TYPES OF GOALS

\begin{tabular}{ll}
\hline Goal & Definition \\
\hline $\begin{array}{c}\text { Self-dependent } \\
\text { (Assigned or self-set) }\end{array}$ & $\begin{array}{l}\text { setting and attaining } \\
\text { a specific standard of } \\
\text { proficiency on a task }\end{array}$ \\
$\begin{array}{ll}\text { Opportunity-dependent } \\
\text { (Self-set) }\end{array}$ & $\begin{array}{l}\text { request for specific } \\
\text { assignment. i.e., request } \\
\text { to be a member of a } \\
\text { particular team }\end{array}$
\end{tabular}

Note. The self-dependent, individual goal is from Locke, Shaw, Saari, \& Latham (1981). The opportunity-dependent, individual goal is derived from the researcher's observation of this field setting.

Opportunity-dependent goals are often used in healthcare organizations. The operating room is a setting in which goal choices are often self-assigned and opportunities are other-dependent. Examples of opportunity-dependent goal choices are requests to learn a different function within the department, or requests to join a specific team or committee. The effects of goal-setting on motivation with OD goals cannot be assumed to parallel those demonstrated in research on self-and other-assigned goals. The OD goal differs in several ways. First, the issue is not self vs other assigned, since the goal is not assigned to the individual by someone else. It is the individual's choice and therefore selfassigned. However, goal achievement is dependent upon the individual being assigned, by management, to a setting in which there is an opportunity (e.g. access to appropriate training and experiences) necessary to reach the goal. The goal is not other-assigned, but the opportunity to accomplish the goal is. This opportunity may or may not be given (assignment made) as a function of individual and/or organizational characteristics. 
The literature on goal-setting has not made this important distinction between these two types (OD and SD) of self-assigned goals. Thus, how these goals might affect the individual's interpretation of success and failure and how this interpretation of success and failure might affect motivation has not been explored in the research. 


\section{LITERATURE REVIEW}

\section{Goal-setting}

Goal-setting motivates action. Goal-setting theory maintains that both the individual and the group types of goals direct human behavior, and that the individual's conscious goals (i.e., purposeful goals) have the most direct and immediate impact on his or her actions (Locke \& Latham, 1984, 1990). Goals are believed to be more immediate to the point of action than needs, values, and generalized attitudes (Locke \& Henne, 1986). These conscious goals directly regulate the individual's effort and performance on a task (Locke \& Latham, 1984, 1990). If the behavior achieves the goal, it is continued and satisfaction results (Bandura, 1986; Locke, Cartiledge, \& Knerr, 1970; Locke \& Latham, 1990). If not, the behavior is abandoned or dissatisfaction follows.

Goals affect performance. Goals motivate the individual to action (Locke, Fredrick, Lee, \& Bobko, 1984), and this motie, vation is cognitively based in (1) anticipation through the use of forethought, and (2) the interaction of goals and self-evaluative responses to one's performance (Bandura, 1977). The anticipation of intrinsic and/or extrinsic rewards from realizing a goal and the standard of the goal itself, used to evaluate the distance from the goal, bring about the motivational effects of goal-setting on performance.

Factors influencing goal-settings effect on performance. Research in organizational settings has shown that if a challenging goal is accompanied by high expectancy of success high performance results, as long as 1) the goal is specific and there is commitment to the goal (Erez \& Zidon, 1984; Locke, Latham, \& Erez, 1988), 2) the goal is valued by the individual (Vance \& Cloella, 1990), 3) specific feedback is given (Erez \& Zidon, 1984; Locke, Latham, \& Erez, 1988; Locke, Shaw, Saari, \& Latham, 1981; Vance \& 
Cloella, 1980), 4) the individual has adequate ability (Locke, 1982), and (5) there are intrinsic rewards (challenge, excitement, enjoyment, accomplishment) and/or extrinsic rewards (pay, benefits, status) which have been found to lead to job satisfaction (Carsten \& Spector, 1986; Jackson, 1983; Mobley \& Locke, 1970; Price \& Mueller, 1977; Rusbult, Farrell, Rogers, \& Mainous III, 1988). Thus, we see that attainable and rewarded goals can lead to satisfaction. The goal should also be challenging or difficult in order to invite greater success which, in turn, will increase performance (Bandura, 1982; Bandura, Adams, Hardy, \& Howells, 1980; Feltz, 1982; Locke, 1976; Locke, et al, 1984; Mobley \& Locke, 1970).

\section{Attribution}

Personal motivational factors and attribution. Attribution is the explanation of one's own and other's behavior as cause and effect relations (Wells \& Harvey, 1977). Personal factors have been found to affect the ways in which people are motivated to explain their own and others' behavior. There is a tendency to attribute good things to the dispositions of friends and bad things to the dispositions of enemies (Regan, Williams, \& Sperling, 1972). This motivational bias has also been found to influence a person's evaluation of their boss' actions (Johnson \& Ewens, 1971).

Heider (1958) discovered that when explaining another's behavior, people focus on internal causes at the expense of external ones. Behavior is attributed to the other's disposition and external causes are ignored. This is termed the "fundamental attribution error." Jones and Nisbett (1971) referred to this as an "actor-observer bias". This bias asserts that though people assume that others' behavior reflects an aspect of that person, their own actions are judged to 
be externally caused. That is, we attend very carefully to what others do so that our focus is on them and we miss what goes on around them, while as for ourselves, as actors, we focus more on the situation and less on our own behaviors (Storms, 1973).

Outcomes and attribution. Event outcomes have been found to influence the individual's attributions in a self-referent way. This "self-serving motivational bias" (Kahneman, Slovic, \& Tversky, 1982), is the tendency for actors to attribute successes to their own efforts, abilities, or dispositions while attributing failure to luck, task difficulty, or other external factors (Davis \& Davis, 1972).

Dimensions of attribution. Researchers have looked at the different components which make up an attribution (Hamilton, 1980; Kelley, 1973; Lord \& Smith, 1983; Weiner, 1979). Weiner (1979) proposed that attributions can be classified according to three dimensions: locus of causality, stability, and control. The causality dimension refers to whether or not the factors relating to an achievement outcome reflect an aspect of the individual (internal) or an aspect of the situation or others (external). "Was my goal outcome dependent on what I or others did or did not do?"

The stability dimension refers to whether the cause is thought to be constant over time (stable, consistent). "Did my own or their behavior differ from what either usually did?"

The control dimension is an evaluation of the ability of one (self or other) to have changed or affected the cause (control, intention). "Could either myself or others have behaved differently to produce a different outcome?" (Hamilton, 1980).

Russell (1982) developed the Causal Dimension Scale (CDS) based on 
the dimensions theorized by Weiner. In order to evaluate the reliability and validity of this scale, Russell, McAuley, and Tarico (1987), endeavored to link a specific dimension of the scale (causality, stability, control) to particular attributions generated by performance success or failure. They found that 1) locus of causality scores are determined by achievement outcome, 2) violations of expectations are related to the stability dimension, and 3 ) locus of causality and controllability are related to affective reactions to success and failure.

Affects of attribution on motivation. Continued motivation to perform has been found to be related to whether the direction of attribution for success is to the self or to other(s) (Bandura, 1977, 1986). Deci (1975) stated that motivation is maintained as long as employees attribute task success to themselves rather than to external factors. These internal attributions must be derived from feelings of personal competence and from their task performance. Deci also found that it is necessary for the employees to believe that they have been able to freely choose to engage in the task and control performance in order for motivation to result. Finally, Bandura and Cervone (1986) maintain that successes are more likely to enhance motivation if performances are perceived as resulting from personal skill rather than external conditions. This indicates that successes, which are causally attributed to others, could not be expected to increase motivation.

\section{Description of Present $\underline{\text { Study }}$}

The investigation was designed to consider the relationship of the independent variable, goal-type and outcome, with the dependent variables, causality, stability, control, and motivation (See Table 2). 
TABLE 2

DEPENDENT VARIABLES

Term

Definition

Causality refers to whether or not the factors relating to an achievement outcome

reflect an aspect of the individual or an aspect of the situation or others.

Stability refers to whether the cause is thought to be constant over time (stable, consistent).

Control refers to an evaluation of the ability of one (self or other) to change or affect the cause.

Motivation the five facets of intrinsic motivation: enjoyment, curiosity, excitement, challenge, and the desire to demonstrate personal competence.

Note. Attribution categories are from Russell (1982). The motivation category is adapted from Deci (1975).

Goal types and outcomes. In this study, the opportunity-dependent (OD) goals are those which require that the management of each healthcare setting make an assignment of the goal-setter to a specific team or responsibility. Examples of this are the goals of joining the open heart team or learning to circulate or scrub on total joint cases. In principle, failure on these OD goals might occur in two ways: first, the individual might not be given the opportunity to attempt the goal (i.e., not be assigned to the team or task) and second, the individual might be given the opportunity (i.e., assigned) but fail at the task. In practice, only the first kind of OD goal failure is likely to occur. For this study, a successful OD goal (ODS) is equivalent to assignment and a failed OD goal (ODF) is equivalent to not being assigned.

Self-dependent goals (SD) are those where assignment and opportunity is 
primarily dependent on the goal- setter. The goal-setter need not rely upon a management decision for some specific assignment. Choosing to become a resource person for the urology service, or choosing to become more proficient on the computer are examples of SD goals. With the SD goal, success (SDS) and failure (SDF) reflect whether the individual, in fact, met the specific standard of proficiency on the task within the specified time limit. Table 3 summarizes the type of goal situations and outcomes that this study examined in selected healthcare organizations.

TABLE 3

INDEPENDENT VARIABLES

Group Label

Abbreviation

External Causality

Opportunity-dependent, success - assigned ODS

Opportunity-dependent, failure - not assigned

ODF

Internal Causality

Self-dependent, success - accomplished

SDS

Self-dependent, failure - not accomplished

SDF

Note. The individuals in both the external and the internal causality groups set their own goals (See table 1).

This study tested whether goal-setting types (OD and SD) influence the individual's attribution of the cause of the goal outcome. It also examined whether the different combinations of goal type and outcome (ODS, ODF, SDS, and SDF) differed in their influence on motivation. 


\section{Hypotheses}

1. Causality

Individuals with ODS and ODF goals will score significantly lower (indicating external causality) on this scale since the opportunity to accomplish the goal outcome was dependent upon management assigning the individual to that job.

Individuals with SDS and SDF goals will score significantly higher (indicating internal causality) because the outcome was self-dependent (See Table 4).

TABLE 4

EXPLANATION OF RESPONSES FOR THE CAUSAL DIMENSION SCALE

\begin{tabular}{lll}
\hline Dimension & Low Score & High Score \\
\hline Causality & External & Internal \\
Stability & Unstable & Stable \\
Control & Uncontrollable & Controllable
\end{tabular}

Note. Causality dimension determines reference for stability and control dimensions.

\section{Stability}

Individuals with ODF goals will score high indicating stable factors of the other or the situation were contributing to the outcome, because (1) the failed outcome would not be contrary to their expectations (Russell et al, 1987), as well as, (2) possibly being influenced by personal motivational factors concerning bad being attributed to the disposition of bosses (Johnson \& Ewens, 1971). Individuals with failed SD goals will score lower (indicating unstable) because the outcome is probably what they expected and failure is not attributed 
to stable characteristics of the self (Russell et al 1987).

\section{Control}

Individuals with ODS, ODF, and SDS goals will score high (indicating control, responsibility, and intention). For ODS and SDS goals, successes are thought to be more controllable by the individual than failures. For the ODF goals, since the questions ask for attributions regarding intention and responsibility, the individual will interpret the other's actions as "they (other(s)) could have done otherwise" and are holding the other accountable.

The individuals with SDF goals will score lower (uncontrollable) due to an "actor/observer" bias which suggests that when evaluating one's own behavior, extenuating circumstances are much more evident than when one is evaluating the behavior of another.

\section{Motivation}

Individuals with SDS goals will score high on the motivation scale following current research findings that success is attributed to internal, stable, and controllable factors that motivate (Locke et al, 1990; Russell, 1982; Russell et al, 1987; Wiener, 1985). Individuals with SDF goals will score high because, although the individual understands that the outcome was dependent on them, they will not blame or hold themselves accountable due to "self-serving motivation and actor/observer biases" (Jones and Nisbett, 1971; Kahneman, Slovic, \& Tversky, 1982). These biases are indicated by the lower scores on stability (this does not indicate a personal characteristic and was not expected) and on control (the situational factors are being taken into account).

Individuals with ODS goals will score in the middle (i.e., higher than 
ODF and lower than SDS and SDF) following current research that suggests that if the person must depend on others, success does not enhance motivation (Bandura, 1986; Deci, 1975).

Individuals with ODF goals will score lower than the other goal conditions because the combination of external, stable, and controllable factors allow blame or accountability to be placed on others. For these individuals, their current behavior has not led to success, therefore, they will either change their behavior and/or become dissatisfied (Bandura, 1986; Locke, Cartiledge, \& Knerr, 1970; Locke \& Latham, 1990).

\section{Joint Influence}

The goal type/outcome conditions, and the three attributional dimensions were expected to explain a significant portion of the variance in motivation, because the relations between the attributional dimensions have been found to mediate the effect of goal-setting on motivation. 


\section{DATA COLLECTION \\ METHOD}

\section{Data-gathering Procedure}

\section{Subjects}

Participants consisted of 83 volunteers (nurses) drawn from a pool of 400 possible subjects employed at 8 local, metropolitan, hospital operating rooms. The sample was comprised of 13 males and 70 females. Of the 83,60 were RNs, 12 were Surgical Technicians, and 4 were Surgical Aides. The group n's were $\mathrm{ODS}=23, \mathrm{ODF}=23, \mathrm{SDS}=22$, and $\mathrm{SDF}=15$.

The questionnaires were administered during regularly scheduled OR staff meetings that were held each day for each shift. This researcher was available at each hospital for one day only from 6 am to $6 \mathrm{pm}$ to present the study to each shift as it came on, to request volunteers, and to answer any questions or concerns that were presented. No follow-up information was gathered, and the subjects participated anonymously. Employee volunteers who had set their goals more than 5 months prior to the questionnaire administration date were invited to participate as subjects in a study examining goal- setting systems. Those who volunteered to participate signed the consent form, which was separated from the questionnaires. They then filled out the questionnaires. They returned both to separate collection points located in the staff lounges.

\section{Independent variables}

The questionnaires were given in random order. Subjects were placed into four levels of the independent variable based on internal/external goals and success/failure outcomes as indicated on the goal questionnaire (see Appendix A): Level 1 opportunity-dependent goal, successful (ODS), Level $\underline{2}$ 
opportunity-dependent goal, failed (ODF), Level $\underline{3}$ self-dependent goal, successful (SDS), and Level $\underline{4}$ self-dependent goal, failed (SDF). Composition of the levels of the Independent Variable were determined by two RN's and one surgical technician. First the raters were given just the goal as written by the subject. The subjects were placed in the opportunity-dependent, OD, and the self- dependent, SD, categories. Rater agreement was $100 \%$ for this phase of the process. Next, for the subjects placed in the OD category, subject's were placed in the outcome conditions for this category based on their yes or no answers to the question, "Were you successful at being assigned to your goal?" For the subjects placed in the SD categories, the subject's were placed in the outcome conditions for this category based on their answer to the question, "Were you successful at accomplishing your goal?"

\section{Dependent Variables}

\section{Attribution}

The dimensions of attribution were assessed using an adapted form of the Causal Dimension Scale (CDS) (Russell, 1982). This scale has been found to accurately assess the individual's explanation for a specific goal success or failure. The scale required the person to reflect on the cause of the event, and then indicate the strength of his or her perception of this cause on nine 7-point scales. There were 3 dimensions each measured by three items: locus of causality (items 1,5,7), stability (items 3,6,8), and control (items 2,4,9) (See Appendix B). The items on the subscales were summed. High scores on these dimensions indicate that the cause is perceived as internal, stable, and controllable. This measurement tool has been found to have good reliability coefficients on the three dimensions; .867 for causality, .837 for stability, and 
.730 for control (Russell et al 1987). Factor analysis (Russell et al, 1987) showed that the scale has construct validity. The causality dimension accounted for $46-59 \%$ of the variance in the items, with very little of the variance explained by the other two dimensions. Discriminent validity was also shown to be adequate (McAuley \& Gross, 1983; Russell, 1982, 1986). Internal consistency reliabilities for this sample on the adapted scales were causality .85 , stability .60 , and control .64.

\section{Motivation}

Motivation was measured using a 6-point Likert scale modified for this study ( $1=$ not at all, $6=$ extremely $)$ in order to assess the degree to which the subjects were certain about their affective responses to the five dimensions of intrinsic motivation: enjoyment, curiosity, excitement, challenge, and the desire to demonstrate personal competence as described by Deci (1975) (See Appendix C). The five scores were added together yielding a total score representative of each subject's subjective motivation. Cronbach's alpha for the motivation scale was .85 for this sample. 


\section{DATA ANALYSIS}

\section{RESULTS}

The first analysis looked at the effect of the goal condition/outcome on the attributional dimensions and motivation. Next, the joint influence of the attributional dimensions (causality, stability, and control) on motivation was examined.

\section{MANOVA}

The independent variable consisted of four groups established by determining the type of goal set for the year and the report of the goal outcome: Opportunity- dependent goals - successful (ODS), opportunity-dependent goals failed (ODF), self-dependent goals - successful (SDS), and self-dependent goals failed (SDF). The dependent variables were causality, stability, control, and motivation, as measured by adapted versions of the CDS and Deci's five measures of intrinsic motivation.

A one-way multivariate analysis of variance was used to analyze Hypotheses 1 through 4 . Wilks' Lambda indicated a significant overall group effect $(\mathrm{F}=5.18 ; \underline{p}<.0001)$. Univariate $\mathrm{F}$-tests indicated group means were significantly different for causality $(\underline{F}=14.06, \underline{p}<.001)$, control $(E=7.13, \underline{p}$ $<.001)$, and motivation $(\underline{F}=3.28, \underline{p}<.03)$, but not for stability $(\underline{F}=1.58, \underline{p}$ $<.20$ ). Table 5 presents the means and standard deviations for each attributional dimension and motivation for every group. 
TABLE 5

MEANS AND STANDARD DEVIATIONS

\begin{tabular}{llrrrr}
\hline & & ODS & ODF & SDS & SDF \\
\hline Causality & M & 13.08 & 5.74 & 13.86 & 8.93 \\
& SD & 6.03 & 5.18 & 5.39 & 5.42 \\
Stability & $\mathrm{M}$ & 12.00 & 10.87 & 11.91 & 8.93 \\
& $\mathrm{SD}$ & 4.46 & 4.71 & 4.71 & 5.06 \\
Control & $\mathrm{M}$ & 17.69 & 16.17 & 16.59 & 11.47 \\
& $\mathrm{SD}$ & 3.76 & 3.95 & 4.69 & 4.96 \\
Motivation & $\mathrm{M}$ & 20.61 & 17.91 & 21.32 & 21.40 \\
& $\mathrm{SD}$ & 3.86 & 5.31 & 3.41 & 3.68
\end{tabular}

Note. Means and Standard Deviations for ODS $n=23$, ODF $n=23$, SDS $n=22$, and $\mathrm{SDF} \mathrm{n}=15$.

\section{Post-hoc Tests}

Newman-Keuls' post-hoc tests were used to test the specific comparisons in Hypotheses 1 through 4. Table 6 depicts the results of the post-hoc tests.

TABLE 6

NEWMAN-KUEL'S POST HOC SIGNIFICANCE TESTS

\begin{tabular}{lll}
\hline Hypotheses & Significant & Non-significant \\
\hline 1. Causality & ODF <ODS, SDS, SDF & ODS Vs SDS \\
2. Stability & SDF <ODS, SDS & ODF vs ODS, SDS, SDF \\
3. Control & SDF <ODF, ODS, SDS & ODF vs ODS, SDS \\
4. Motivation & ODF <ODS, SDS, SDF & SDF vs ODS, SDS
\end{tabular}

Note. Patterns of responses based on Newman-Keuls' post-hoc test results indicating significant differences between the means.

Hypothesis 1 stated that the individuals with opportunity-dependent goals, OD goal type, would score significantly lower on causality than the 
individuals with self-dependent goals, SD goal type. The data supported this hypothesis for failures only. The successful goal outcomes, ODS and SDS, were not significantly different whereas ODF was significantly lower than SDF on the causality dimension.

Hypothesis 2 examined the stability dimension. It was predicted that the ODS group and the SDF group would score significantly lower than the ODF group and the SDS group on the stability dimension. It was found that there were no significant differences in the four group means.

Hypothesis 3 tested differences on the control dimension and stated that SDF would score significantly lower than ODF. It was predicted that SDF would also score lower on the control dimension than either of the successful goals, ODS and SDS. This hypothesis was supported as SDF did score significantly lower than ODS, ODF, and SDS.

Hypothesis 4 predicted that motivation for individuals with opportunitydependent goals would be significantly lower than for individuals with selfdependent goals. In addition, ODF was expected to produce the lowest score. ODF was found to be significantly lower on motivation than the other 3 groups. There were no significant differences between the means of ODS and the two self-dependent goals, SDS and SDF.

\section{Regression Analysis}

Hypothesis 5 explored the amount of variance accounted for in motivation by the goal condition/outcome group and the attributional dimensions. It stated that the attributional dimensions and goal condition/outcome would account for a significant proportion of variance in 
motivation. In order to test Hypothesis 5, a hierarchical multiple regression was used to identify the contribution of goal condition/outcome and the attributional dimensions to motivation. The three attributional dimensions were entered into the model first. Results of the multiple regression analysis indicated that causality, stability, and control accounted for a significant amount of the variance in motivation $\left(\mathrm{R}^{2}=.1163 ; \mathrm{F}=3.48 ; \mathrm{p}<.02\right)$. Both causality $(\mathrm{B}=$ $.287 ; \mathrm{p}<.012)$ and stability $(\mathrm{B}=-.283 ; \mathrm{p}<.018)$ had significant regression coefficients, signifying a unique significant contribution. Next, coded vectors of the 4 levels of the IV were entered into the model. When these goal condition/outcome levels were added to the model, variance accounted for increased to $18.05 \%(\underline{F}=2.79 ; \underline{p}<.017)$. This increase was significant $(\underline{F}>$ $2.72 ; \mathrm{p}<.02)$. The significant regression coefficients in the second step of the model were stability $(B=-.262 ; p<.027)$ and the coded vector that compared ODF and SDF $(B=-.350 ; p<.028)$. The regression analysis found that $18 \%$ of the variance in motivation can be explained by the attributional dimensions and goal condition/outcome.

Stability and differences between the two failure groups contributed uniquely to the variance accounted for in motivation (See Table 7). 
TABLE 7

REGRESSION ANALYSIS

\begin{tabular}{lccccc}
\hline Model 1 & $\mathrm{b}$ & $\mathrm{B}$ & $\mathrm{SE}$ & $\mathrm{t}$ & $\mathrm{p}$ \\
\hline Causality & 0.216 & 0.287 & 0.084 & 2.57 & $0.012^{*}$ \\
Stability & -0.261 & -0.283 & 0.108 & -2.42 & $0.018^{*}$ \\
Control & 0.080 & 0.085 & 0.108 & 0.74 & 0.462 \\
& & & & & $\mathrm{t}$ \\
\hline Model 2 & $\mathrm{b}$ & $\mathrm{B}$ & $\mathrm{SE}$ & $\mathrm{p}$ \\
\hline Causality & 0.111 & 0.147 & 0.101 & 1.10 & 0.276 \\
Stability & -0.240 & -0.262 & 0.106 & -2.26 & $0.027^{*}$ \\
Control & 0.157 & 0.175 & 0.116 & 1.35 & 0.180 \\
ODS vs SDF & -1.497 & -0.154 & 1.556 & -2.26 & 0.339 \\
ODF vs SDF & -3.409 & -0.350 & 1.524 & -2.24 & $0.028^{*}$ \\
SDS vs SDF & -0.265 & -0.063 & 1.539 & -0.41 & 0.686
\end{tabular}

* significant at alpha $=.05$

Note. Model $1 \mathrm{~F}=3.467, \mathrm{p}<0.020$. Model $2 \mathrm{~F}=2.789, \mathrm{p}<0.017$. Increment in $\mathrm{R} \mathrm{F}>2.72, \mathrm{p}<0.02$. 


\section{DISCUSSION}

This research demonstrated that the relationship between successful outcomes and attribution and motivation, regardless of goal condition, follows previous research, but that failure outcomes do not. It was found that for both the opportunity-dependent and self- dependent goal groups successes are attributed to internal causes that are perceived as being highly controllable, and that success is related to higher motivation. However for failures this study did not agree with previous research which found that failures are attributed to external causes that are perceived as being less stable and controllable, and that failures are do not motivate. This study found that failed, self- dependent goals were related to higher motivation. The ODF group did follow prior research regarding failure's effect on motivation, but not for the relations between the attributional dimensions. In this study, the failed, opportunity-dependent goals were related to the lowest motivation.

\section{Differences in Causality}

High scores on the causality dimension indicate an attribution to internal causes. Even though the goal outcome for OD was opportunity-dependent and the goal outcome for SD was self-dependent, both of these successful goal outcome groups, ODS and SDS, judged the cause to be more internal than did either of the groups ODF and SDF. These results are consistent with the research literature that found successes to be attributed to internal causes and failures to external causes (Bandura, 1986; Russell, 1982).

The ODF group scored significantly lower on causality than did the SDF 
group. This would indicate that the individuals who failed to achieve an opportunity-dependent goal perceived the cause as being more external than the individuals who failed at the self-dependent goal. Research by Bandura (1986) and Russell (1982) suggests that both failure groups should score low on causality (i.e., see causes as external). The finding that the ODF group was lower than the SDF group is contrary to their research and may indicate a new partition for investigating external causality. The OD/SD distinction produces a delineating variable that distinguishes among failures and not among successes.

\section{Differences in Stability}

High scores on the stability dimension indicate that the cause is attributed to stable factors. The questions on the CDS elicit judgments from the individual as to whether the cause is temporary or permanent, variable over time or stable over time, and changeable or unchanging. The stability dimension answers the question -- "Did my own or their behavior differ from what either usually did?" There were no significant differences for the groups for either internal/external attributions or success/failure outcomes for the stability dimension.

As indicated earlier, even though stability did not demonstrate significant differences between the means, stability did contribute significantly to the variance found in motivation. This indicates that the individual's evaluation of whether or not her/his own or the other's behavior differed from what either usually did was not related to goal type or outcome, however, it did influence motivation. This will be discussed further in the regression section. 


\section{Differences in Control}

For the successful goal outcomes, as well as for the failed, opportunitydependent goal outcome, control was perceived as being significantly higher than for the failed, self-dependent goal. High scores on the control dimension indicate that the individual feels either they or others had control of the outcome, i.e., "I could have done otherwise." "They could have done otherwise." Low scores indicate that the individual feels that neither they nor others could have done otherwise.

It is clear that individuals with successful goals attributed causality to internal factors and are attributing control as well as intention and responsibility for the goal success to themselves (see CDS items, Appendix B). ODF goals also were related to high scores on the control dimension. Causality scores for these individuals indicate that they view other(s) or the situation as opposed to themselves as having control of the outcome, to have intended it, and to be responsible for the failure. SDF groups attributed failure to external causes and perceived these external causes as having little control, intention, and responsibility for the goal failure. The SDF group saw the reasons for their failures as being uncontrollable. Thus, it would appear that they may be using an actor/ observer bias (Jones \& Nisbett, 1971) that allows them to see the extenuating circumstances within the situation that influence their own and other's behavior which would allow them to not hold anyone or anything as responsible.

It is apparent that the OD/SD distinction produced different control attributions that differentiate among failures but not among successes. The ODF group perceived the external cause to be more controllable than did SDF. 


\section{Differences in Motivation}

Research has found that goal successes motivate, and that goal failures do not motivate (Bandura, 1986; Locke et al, 1984; Russell, 1982). This study lends support to past research as successes were found to produce higher motivation for both OD and SD goals. The OD/SD distinction was related to different levels of motivation for the failure groups due to differences in the joint influence of the attributional dimensions. The motivation from SDF goals was equivalent to the motivation for successful goals and higher than the motivation for ODF goals.

\section{Joint Influence of the Attributional Dimensions}

The multiple regression found that $12 \%$ of the variance in motivation can be explained by the joint influence of causality, stability, and control. Both causality and stability had significant unique contributions. The goal/outcome situations accounted for $6 \%$ of the variance in motivation not explained by the attributional dimensions. Only the unique influence of stability remained significant after adding the goal/outcome variable.

The causality dimension is used to determine the reference for the stability and control dimensions. It may be argued that because the causality dimension did not produce the internal/external split as predicted, this dimension could no longer be assumed to be determining the reference for the other dimensions. Russell et al. (1987) make it clear that it is the joint influence of all three dimensions that is most important. This is what the regression analysis tests. In this study, the relations between the attributional dimensions are significantly affecting motivation, with increases in causality and decreases in 
stability leading to increases in motivation.

Russell (1982, 1987; Wiener, 1982) found that perceptions of higher causality, higher stability, and higher control led to higher motivation. The stability dimension is also discussed by theorists investigating learned helplessness. They found that attributions increasing in stability and decreasing in control resulted in lower motivation (Abramson, Seligman, \& Teasdale, 1978; Maier \& Seligman, 1976; Mikulincer, 1988). In this study it was found that as causality and control increased and stability decreased, motivation increased.

This study also demonstrated that the effect of stability on motivation persists after controlling for goal type and outcome. However, the effect of causality is no longer significant after controlling for goal type and outcome. Causality's effect on motivation is related to differences in goal type and outcome, but not stability's effect on motivation. 


\section{IMPLICATIONS FOR THE HOSPITAL SETTING}

It is thought that one method of encouraging change in present hospital practices is to identify the effects of practices on employee attributions to locus of causality, stability, control, and the joint effect of attributions on motivation. The results of this research help to clarify the effects of the current goal-setting practices on the employee's motivation by contributing to the understanding of the joint influence of the attributional dimensions on motivation in the workplace. This study added to the idea of Weiner (1979) and Russell (1982, 1987) that it is the joint influence of the attributional dimensions as they combine with goal type that regulates their impact and allows them to contribute significantly to the variance in motivation.

The applied question consisted of two parts. (1) Are opportunitydependent goals often set by individuals in organizations? (2) What are the effects of these different goal types on motivation? OD goals are often set in hospitals and impact motivation by lowering motivation when the individual is not assigned to the goal chosen. ODF goals are related to the lowest motivation. These individuals have not really had the opportunity to succeed or fail by directing their own efforts. This type of goal, if the opportunity is not assigned, gives no direction for continuing behaviors (Bandura, 1977). This lack of opportunity elicits attributions to external causes and low motivation. The current literature would suggest that this may result in abandonment of current behavior, and/or dissatisfaction with the job, the management, or the organization (Bandura, 1986; Locke et al, 1970, 1990).

Perhaps, the most judicious way to adapt the current system to increase motivation would be to insure that all individuals with opportunity-goals are assigned. However, this is not always practical. The individual may not have 
the ability, the organization may not require additional individuals to be proficient in that area, the cost of training individuals may not be feasible at the time, or the individual may be of more value to the organization in their current position. These factors indicate that the opportunity may or may not be given (assignment made) as a function of individual and/or organizational characteristics. However, unless the reason for non-assignment is expressed to the individual, perceptions of external causality and control would be expected to persist.

Another option would be to require all goals to be self-dependent goals. However, as the opportunity-goals are important in knowing which individuals are interested in being trained for inclusion in a different specialty, these requests still need to be solicited. It is also helpful to know which individuals feel they are ready to take on this new challenge in order to avoid assigning individuals who do not feel they are ready. This could greatly increase job stress if they feel pressured to comply when they are in over their heads.

Applying the results of this study to address both the organizational needs and the goal-setting practices already in effect, the goals that have been shown to motivate need to be set and the potential for allowing individuals the chance to blame others decreased. To accomplish this, both OD and SD goals could be elicited for each person. Then, applying the research delineating effective goal-setting, cited previously, the factors observed to be most mutable would be those of feedback and specificity. The opportunity-dependent goals could be adapted to incorporate outcome and process feedback concerning the individual's ability, the organization's need, and the individual's progress (Bandura, 1989; Earley, Northcraft, Lee, \& Lituchy, 1990). Both the goal and 
the feedback would have to be specific rather than vague (Erez \& Zidon, 1984; Locke, Latham, \& Erez, 1988). Another necessary factor is that the opportunity- dependent goals be accepted and committed to by both the individual and the organization (Locke, Latham, \& Erez, 1988; Vance \& Cloella, 1990) in order for the individual to receive the necessary assignment, training, and support elements (Freedman \& Phillips, 1985; Peters, Chassie, Lindholm, O'Connor, \& Kline, 1982). The SD goals, also, would have to be specific in order to obtain measurable parameters for success or failure. For example, the goal of becoming a certified specialist in the OR is specific and measurable, whereas the goal to become a urology resource person is open to subjective evaluation. 


\section{CONCLUSION}

\section{Limitations of the Study}

The usefulness of this design was enhanced by the field setting. The individuals in this study had educational levels from two to five years beyond high school and personal knowledge of the organization and their co-workers. However, this setting did not produce the number of subjects expected. The pool consisted of approximately 400 subjects from 8 different hospitals and less than one fourth responded $(n=83)$.

Another drawback to this study was that the goal questionnaire (See Appendix A) should not ask for answers to both of the questions; were you successful in being assigned and if your goal did not require assignment, did you accomplish your goal? Many subjects with opportunity-dependent goals answered both questions. For the subjects in the successful, opportunitydependent goal categories, answering both questions may have allowed the individual to change from considering the goal as external and requiring assignment to being internal because they considered themselves successful after having been assigned.

Another drawback was the difficulty in interpreting the Causal Dimension Scale with respect to causality, stability, and control. Both OD and SD groups made attributions to external causes. The specific questions on the CDS for the causality dimension ask whether (1) the cause reflects an aspect of the situation or an aspect of yourself (2) the cause is something about others or something about you, and (3) the cause is something outside of you or inside of you. The question arises as to whether the individual has attributed the external cause to other, situational factors, or both. If it is to other(s), then the degree of stability and control should be an evaluation of a person or persons' stable 
characteristics and her/his ability to have done otherwise (control). If it is to the situation, the evaluation should be of the situation's degree of stability and its ability to have done otherwise (control). However, if causality is to both (e.g., when both other and situation are designated), then the interpretation of stability and control would be much more difficult.

A similar area of confusion occurred in the interpretation of the control dimension. The OD/SD distinction has made it necessary to clarify whether the attributional dimension control is being used to evaluate the self, situation or other. For example, when an individual who has failed at a self-dependent goal attributes the cause to external factors, does the stability dimension assess the stability of this external cause or the self, and does the control dimension assess the control of this external cause over the outcome, or the control of the individual over these external causes. Do low scores denote both less personal control and greater control to others?

The specific questions that elicit attributions for control, intention, and responsibility are (1) Is the cause(s) controllable by you or other people? Uncontrollable by you or other people? (2). Intended by you or other people? Unintended by you or other people? (3) Something for which someone is responsible? No one is responsible? When only SD goals are being studied, these questions are explicit enough, however, the study of OD and SD goals would profit from more vigorous delineation.

\section{Future Research}

There are a number of interesting ideas that will need to be addressed in future research. Suggestions for future research include 1) Examination of 
opportunity- dependent goals that would include a manipulation of the independent variable in both the laboratory and other field settings. 2) Examination of whether the individuals with OD and SD goals are both continuing to make attributions in the same direction indicated by the causality dimension. Research to date has not incorporated the OD/SD distinction. Russell et al (1987) found that control was related to affective reactions to failure. Their results could be even further investigated and clarified using the $\mathrm{OD} / \mathrm{SD}$ distinction. Using this distinction, the exploration of the elicitation of praise and blame (Russell et al, 1987), as incorporated in the attributional dimensions, would give more understanding about possible effects on job satisfaction, organizational commitment, and other measurements of performance motivation, as well as turnover.

The relationship of how failed opportunity goals relate to the individual's expectations and the effect on motivation should be investigated further. The stability dimension was found, by Russell et al (1987), to be associated with the individual's outcome expectation. Learned helplessness theorists also found that stability was associated with expectations finding that stability increases either as successes are accumulated or as more failures are experienced. Finding the constancy of the attributional patterns and the effect of these patterns on motivation scores should be examined for the OD and the SD goals, as well as factors, such as goal feedback and specificity, that influence the patterns elicited for the attributional dimensions. 


\section{SUMMARY}

Opportunity-dependent goals have been shown to be related to decreases in motivation when the individual is not assigned. This type of goal appears to be an ineffective application of goal-setting. Options for changing the effects of this goal-type in the workplace have been given. An awareness of the existence of this type of goal allows one to see its presence throughout society. For example, when the athlete has goals for when he/she plays, but the coach never puts them in the game. Or, when the teacher has a goal of being on the curriculum committee and is not given that opportunity. The pervasive setting of opportunity-dependent goals makes continuing investigation into its effects a priority, and alleviation of any negative effects a challenge. 


\section{REFERENCES}

Bandura, A. (1977). Self-efficacy: Toward a unifying theory of behavioral change. Psychological Review, Vol. 84, 191-215.

Bandura, A. (1982). Self-efficacy mechanism in human agency. American Psychologist, Vol. 37, 122-147.

Bandura, A. (1986). Social foundations of thought and action: A socialcognitive view. Englewood Cliffs, NJ: Prentice Hall.

Bandura, A., Adams, N. E., Hardy, A. B., \& Howells, G. N. (1980). Tests of the generality of self-efficacy theory. Cognitive Therapy and Research, Vol. 4, 39- 66.

Bandura, A., \& Cervone, D. (1986). Differential engagement of self-reactive influences in cognitive motivation. Organizational Behavior and Human Decision Processes, Vol. 38, 92-113.

Davis, W. L. \& Davis, D.E. (1972). Internal-external control and attribution of responsibility for success and failure. Journal of Personality, 40, 123-136.

Deci, E. L. (1975). Intrinsic Motivation. New York: Plenum Press.

Erez, M., \& Zidon, I. (1984). Effect of goal acceptance on the relationship of goal difficulty to performance. Journal of Applied Psychology. Vol. 69, 69-78.

Feltz, D. L. (1982). Path analysis of the causal elements in Bandura's theory of self-efficacy and an anxiety-based model of avoidance behavior. Journal of Personality and Social Psychology, Vol. 42, 764-781.

Hamilton, V. L. (1980). Intuitive psychologist or intuitive lawyer? Alternative models of the attribution process. Journal of Personality and Social 
Psychology, Vol. 39, 767-772.

Heider, F. (1958). The Psychology of Interpersonal Relations. New York:

Wiley, pp 146-147.

Johnson, M. \& Ewens, W. (1971). Power relations and affective style as determinants of confidence in impresion formation in a game situation. Journal of Experimental Social Psychology, Vol. 7, 98-110.

Jones, E. E. \& Nisbett, R. E. (1971). The actor and the observer: Divergent perceptions of the causes of behavior. in E. E. Jones, Kanouse, D., Kelley, H. H., Nisbett, R. E., Valins, S., \& Weiner, B. Attribution: Perceiving the Causes of Behavior. Morristown, N. J.: General Learning Press.

Kahneman, D., Slovic, P, \& Tversky, A. (1982). Judgment Under Uncertainty: Heuristics and Biases. Cambridge University Press. Kelley, H. H. (1973). The processes of causal attribution, American Psychologist, 107-128.

Locke, E. A., Cartledge, N., \& Knerr, C. S. (1970). Studies in the relationship between satisfaction, goal setting and performance.

Organizational Behavior and Human Performance, Vol. 5, 135-158.

Locke, E. A. (1976). The nature and causes of job satisfaction. M. D.

Dunnette (Ed.), Handbook of Industrial and Organizational Psychology. Chicago: Rand McNally.

Locke, E. A. (1982). Relation of goal-level to performance with a short work period and multiple goal levels. Journal of Applied Psychology, Vol. 67, 512-514.

Locke, E. A., \& Henne, D. (1986). Work motivation theories. In C. Cooper \& I. Robertson (Eds.), International review of industrial and organizational psychology, Chichester, England: Wiley Ltd. 
Locke, E. A., Shaw, K. N., Saari, L. M., \& Latham, G. P. (1981). Goalsetting and task performance: 1969-1980. Psychological Bulletin.. Vol. $90,125-152$.

Locke, E. A., Fredrick, E., Lee, C., \& Bobko, P. (1984). The effect of selfefficacy, goals, and task strategies on task performance. Journal of Applied Psychology, Vol. 69, 241-251.

Locke, E. A., \& Latham, G. P. (1984). Goal-setting: A Motivational Technique that Works. Englewood Cliffs, NJ: Prentice Hall.

Locke, E. A., \& Latham, G. P. (1990). Work motivation and satisfaction. Psychological Science, Vol. 1, No. 4, 240-245.

Locke, E. A., Latham, G. P., \& Erez, M. (1988). The determinants of goal commitment. Academy of Management Review, Vol. 13, No. 1, 23-39.

Lord, R.G., \& Smith, J.E. (1983). Theoretical, information processiong, and situational factors affecting attribution theory models of organizational behavior. Academy of Management Review $3,50-60$.

Mikulincer, M. (1988). The relation between stable/unstable attribution and learned helplessness. British Journal of Social Psychology, 27, 221-230.

Mobley, W. H., \& Locke, E. A. (1970). The relationship of value importance to satisfaction. Organizational Behavior and Human Performance, 5, 463-483.

Regan, D. T., Williams, M., \& Sparling, S. (1977). Voluntary expiation of guilt: A field experiment. Journal of Personality and Social Psychology. Vol. 24, 42-45.

Rusbult, C. E., Farrell, D., Rogers, G., \& Mainous III, A. G. (1988). Impact of exchange variables on exit, voice, loyalty, and neglect: An integrative model of responses to decling job satisfaction. Academy of Management 
Journal, Vol. 31, 599-627.

Russell, D. (1982). The causal dimension scale: A measure of how individuals perceive causes. Journal of Personality and Social Psychology, 42. 1137-1145.

Russell, D., McAuley, E., \& Tarico, V. (1987). Measuring causal attributions for success and failure: A comparison of methodologies for assessing causal dimensions. Journal of Personality and Social Psychology, Vol. 52, No. 6. 1248-1257.

Storms, M. D. (1973). Videotape and the attribution process: Reversing actors' and observers' points of view. Journal of Personality and Social Psychology, Vol. 27, 165-175.

Vance, R. J., \& Cloella, A. (1990). Effects of two types of feedback on goal acceptance and personal goals. Journal of Applied Psychology. Vol. 75, No. 1, 68-76.

Weiner, B. (1979). A theory of motivation for some classroom experiences. Journal of Educational Psychology 2 71, 3-25.

Wells, G. L. \& Harvey, J. H. (1977). Do people use consensus information in making causal attributions? Journal of Personality and Social Psychology, Vol. 35, 279-293. 


\section{APPENDIX A}

\section{DEMOGRAPHIC AND GOAL DATA SHEET}

Your sex:

(1) Female

(2) Male

Your age: years

What is your primary position? (check only one)

(1) $\mathrm{RN}$

(2) LPN

(3) Surgical Technician

(4) Aide

\section{Questions:}

1. What goal did you choose during your performance review this year? Be specific.

2. Has it been 5 months since you set this goal? Yes

No

3. Have you missed more than two consecutive weeks of work since you set your goal? Yes _ No

4. What was the goal outcome?

Were you successful in being assigned?

Yes No

If your goal did not require assignment, did you accomplish your goal?

Yes No 


\section{APPENDIX B}

\section{ATTRIBUTION QUESTIONNAIRE}

Instructions: Think about the reason you were successful in gaining assignment, or if you did not need to be assigned, think about the reason for your goal success/failure. The items below concern your impressions or opinions of the major cause of your goal success or failure. Mark one box for each of the questions below.

1. Is the cause something that reflects

An aspect

of the situation

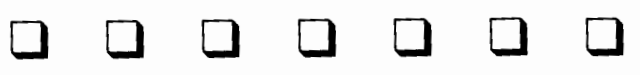

An aspect

of yourself

2. Is the cause
Uncontrollable by you
or other people
Controllable by you or other people

3. Is the cause something

Temporary

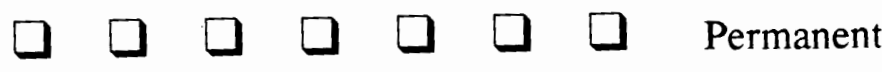

4. Is the cause something

Unintended by you or other people

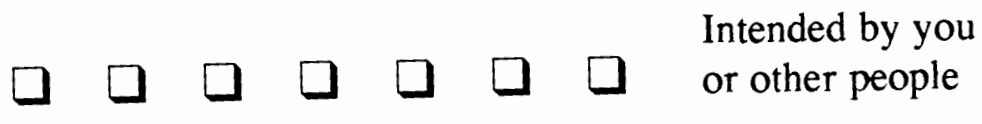

5. Is the cause something Outside of you
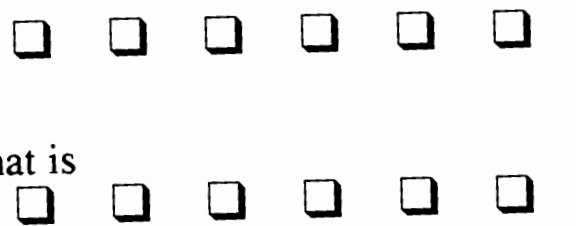

$\square \quad$ Inside of you

6. Is the cause something that is

Variable over time

$\square \square \square \square \square \square \quad$ Stable over time

7. Is the cause

Something about

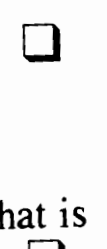

others

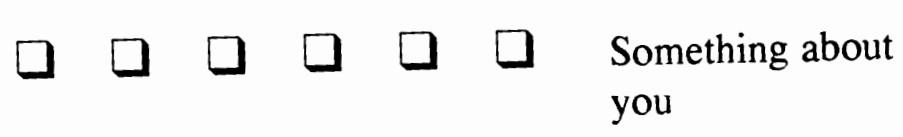

8. Is the cause something that is

Changeable

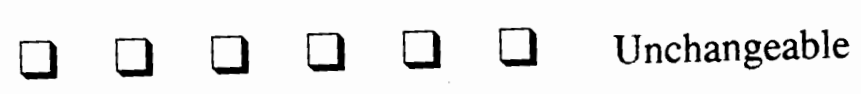

9. Is the cause something for which

No one is

responsible

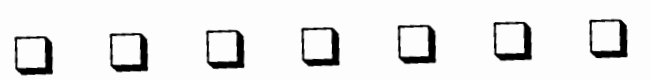

Someone is responsible 


\section{APPENDIX C \\ Motivation Questionnaire}

Instructions: The items below concern how you feel about your job at this hospital. Circle one number for each of the following statements, that best reflects the degree each statement is true for you.

I feel challenged by my job.

$\begin{array}{cccccc}\text { Not at all } & \text { Slightly } & \text { Somewhat } & \text { Considerably } & \text { A great deal } & \text { Extremely } \\ 1 & 2 & 3 & 4 & 5 & 6\end{array}$

I feel curiosity about different aspects of my job.

$\begin{array}{cccccc}\text { Not at all } & \text { Slightly } & \text { Somewhat } & \text { Considerably } & \text { A great deal } & \text { Extremely } \\ 1 & 2 & 3 & 4 & 5 & 6\end{array}$

I feel excitement about my job.

$\begin{array}{cccccc}\text { Not at all } & \text { Slightly } & \text { Somewhat } & \text { Considerably } & \text { A great deal } & \text { Extremely } \\ 1 & 2 & 3 & 4 & 5 & 6\end{array}$

I feel enjoyment in doing my work here.

$\begin{array}{cccccc}\text { Not at all } & \text { Slightly } & \text { Somewhat } & \text { Considerably } & \text { A great deal } & \text { Extremely } \\ 1 & 2 & 3 & 4 & 5 & 6\end{array}$

I feel a desire to demonstrate my personal competence at my job.

Not at all Slightly Somewhat Considerably A great deal Extremely 